\title{
Valuing ecotourism in Bukit Merah Orang Utan Island, Malaysia based on visitors' experience
}

\author{
NABILA FARHANA MOHD-ASRI ${ }^{1}$, SITI NORSYUHADA KAMALUDDIN ${ }^{1}$, SABAPATHY DHARMALINGAM ${ }^{2}$, \\ WAN MOHD RAZI IDRIS ${ }^{1}$, BADRUL MUNIR MD-ZAIN ${ }^{1,2, \vee}$ \\ ${ }^{1}$ Department of Biological Sciences and Biotechnology, Faculty of Science and Technology, Universiti Kebangsaan Malaysia. 43600, Bangi, \\ Selangor, Malaysia. Tel.: +60-389-215954,`email: abgbadd@ukm.edu.my, abgbadd1966@yahoo.com \\ ${ }^{2}$ Bukit Merah Orang Utan Island Foundation. Bukit Merah, Perak, Malaysia
}

Manuscript received: 6 February 2021. Revision accepted: 27 February 2021

\begin{abstract}
Mohd-Asri NF, Kamaluddin SN, Dharmalingam S, Idris WMR, Md-Zain BM. 2021. Valuing ecotourism in Bukit Merah Orang Utan Island, Malaysia based on visitors' experience. Biodiversitas 22: 1543-1549. Ecotourism has been identified as one of the alternative ways of boosting a region's economic status and highlighting the necessity of a healthier tourism sector. Bukit Merah Orang Utan Island (BMOUI) is the only ex-situ conservation center promoting primate ecotourism on the Malay Peninsula. We conducted a primate ecotourism survey at BMOUI to determine six ecotourism expressive valuations for describing the quality of tourists' visits to BMOUI and estimating tourist's willingness to pay (WTP) in relation to the entrance fee. Surveys were completed by 100 randomly selected respondents aged at least 18 years. Likert scale items and Cronbach's alpha were used in the data analyses. Six ecotourism experiences (hedonic, interaction, novelty, comfort, stimulation, and safety values) were further analyzed using statistical software. The results showed that visitors experienced moderate hedonic experience (44.8\%), moderate interactive value $(42.35 \%)$, moderate novelty value $(42.5 \%)$, medium comfort value $(42.5 \%)$, medium stimulation value $(42.7 \%)$, and low security value (37.15\%). In addition, the mean WTP, determined by the bidding process, was about RM54.90 per visitor for each visit. The findings of ecotourism experiences and the estimated price can provide important information to BMOUI administrators. This study will contribute indirectly to upgrading the level of awareness of primate conservation aspects among tourists, entrepreneurs, and locals.
\end{abstract}

Keywords: Primate ecotourism, orangutan, expressive valuation, willingness to pay, primate conservation

\section{INTRODUCTION}

Ecotourism is the combination of tourism markets and the application of ecofriendly practices for developing sustainable natural resources (Ouattara et al. 2016). Ecotourism is also known as a powerful tool for generating human experience with economic, sociocultural, and environmental benefits (Aznie et al. 2012). This sector offers nature experiences to travelers, especially in environmental education and conservation knowledge, as well as increasing public awareness about the environment (Aznie et al. 2012). Ecotourism includes local communities to expand the area without causing any environmental destruction or creating social conflicts related to the development (Chougule 2011). It simultaneously minimizes human impact and helps the local community conserve and preserve natural resources, such as flora and fauna (Ahmad and Pandey 2016; Choy et al. 2012).

According to Chu-Chai et al. (2007), ecotourism has five basic features that can be applied for conservation, as follows: the centers of protection, benefit theory to the population, return of the nature theory, theory of responsibility, and theory of primitive deserts (Chu-Chai et al. 2007). In addition, other factors, such as hedonism, interactivity, novelty, comfort, safety, and stimulation, are important for enhancing ecotourism site operators' management and services. These factors enable ecotourism operators to review their service experience so that positive feedback will be obtained from tourists during their trips (Chan and Baum 2007; Otto and Richie 1996).

One of the primate conservation areas that has attracted the attention of Malaysians and foreigners on the Malay Peninsula is Bukit Merah Orang Utan Island (BMOUI). This primate ecotourism site was officially inaugurated by the former prime minister of Malaysia in 1999 (Dharmalingam 2016). BMOUI consists of 35 acres of land surrounded by Bukit Merah Lake; with 5 acres functioning as an ex situ rehabilitation and conservation center for Bornean orangutan (Dharmalingam 2016). In 2000, this island was a temporary home to three orangutans that had been rescued from illegal trade (Dharmalingam 2016). By 2020, the number of orangutans had risen to about 18 . The main goals of BMOUI are conservation, education, breeding, research, and ecotourism (Kamaluddin et al. 2018, 2019).

Many studies on primatology have been conducted in Peninsular Malaysia, including ecology, behavior, and genetics aspects (Abdul-Latiff et al. 2019a; Md-Zain et al. 2019; Osman et al. 2020; Ruslin et al. 2019). Few published reports are available related to primate ecotourism in Peninsular Malaysia (Abdul-Latiff et al. 2019b,c, Najmuddin et al. 2019, Siti-Kauthar et al. 2019). However, there is a lack of ecotourism data on the uniqueness of this location, which should be emphasized as a good ecotourism site involving primate conservation in Malaysia. Here, BMOUI was chosen as the study site because this place offers an ecotourism experience, where 
the tourists have face-to-face experiences with the orangutan in their semi-natural habitat. In addition, BMOUI has been touted by many authorities as one of the ecotourism spots in Peninsular Malaysia. Therefore, we conducted an ecotourism survey to determine tourists' responses to responsible visits to BMOUI. We determined six expressive ecotourism valuations that describe the quality of tourists' visits to BMOUI and sought to estimate the tourists' willingness to pay (WTP) regarding the entrance fee. The valuations were carried out based on six expressive valuations that were introduced and integrated from Chan and Baum (2007) and Otto and Ritchie (1996). The survey will help in delineating the suggested economic value of ecotourism-based visits by identifying BMOUI as a primate ecotourism site.

\section{MATERIALS AND METHODS}

\section{Study site}

This study was conducted in BMOUI, located in the state of Perak, Peninsular Malaysia $\left(100^{\circ} 40.6^{\prime} \mathrm{E}, 05^{\circ} 0.50^{\prime} \mathrm{N}\right.$; Figure 1). Visitors pay a ticket at the jetty, taking a boat ride from the mainland to reach Orang Utan Island. BMOUI covers an area of about 35 acres of dipterocarp forest land. There are indoor and outdoor enclosures on a 5-acre area of the island (Dharmalingam 2016). The orangutans are housed in the indoor enclosure every evening until the next morning before they are released into the outdoor enclosure (Figure 2). In the exhibit area, visitors go through a tunnel for sighting orangutans roaming freely in the outdoor exhibit.

\section{Data collection and analysis}

Random surveys were among visitors to BMOUI in JulyAugust 2016. Throughout research period, about 100 respondents were randomly selected to participate during their BMOUI visits. To complete the surveys, two main respondent criteria needed to be fulfilled. First, the tourists as respondents needed to complete the survey concerning their BMOUI experience during their visit. The second criterion was the tourists' ability to understand the English language. We only included respondents aged 18 years or older to ensure that reliable responses could be obtained. In addition, only one representative of a group trip was chosen randomly to prevent repetition of the responses and to obtain unbiased responses. The respondents were given about 5-10 minutes to fill out the answers to all the questions.

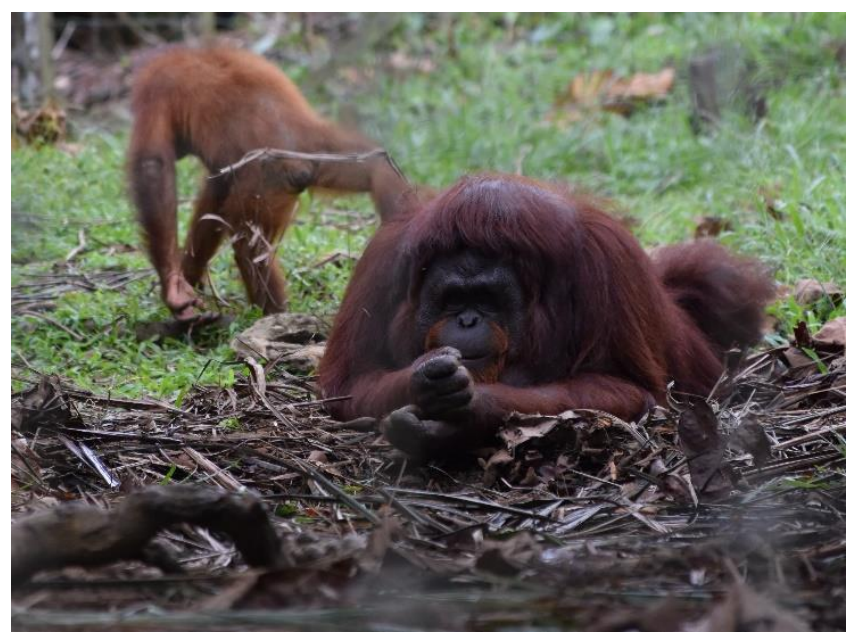

Figure 2. Orangutan at BMOUI outdoor enclosure
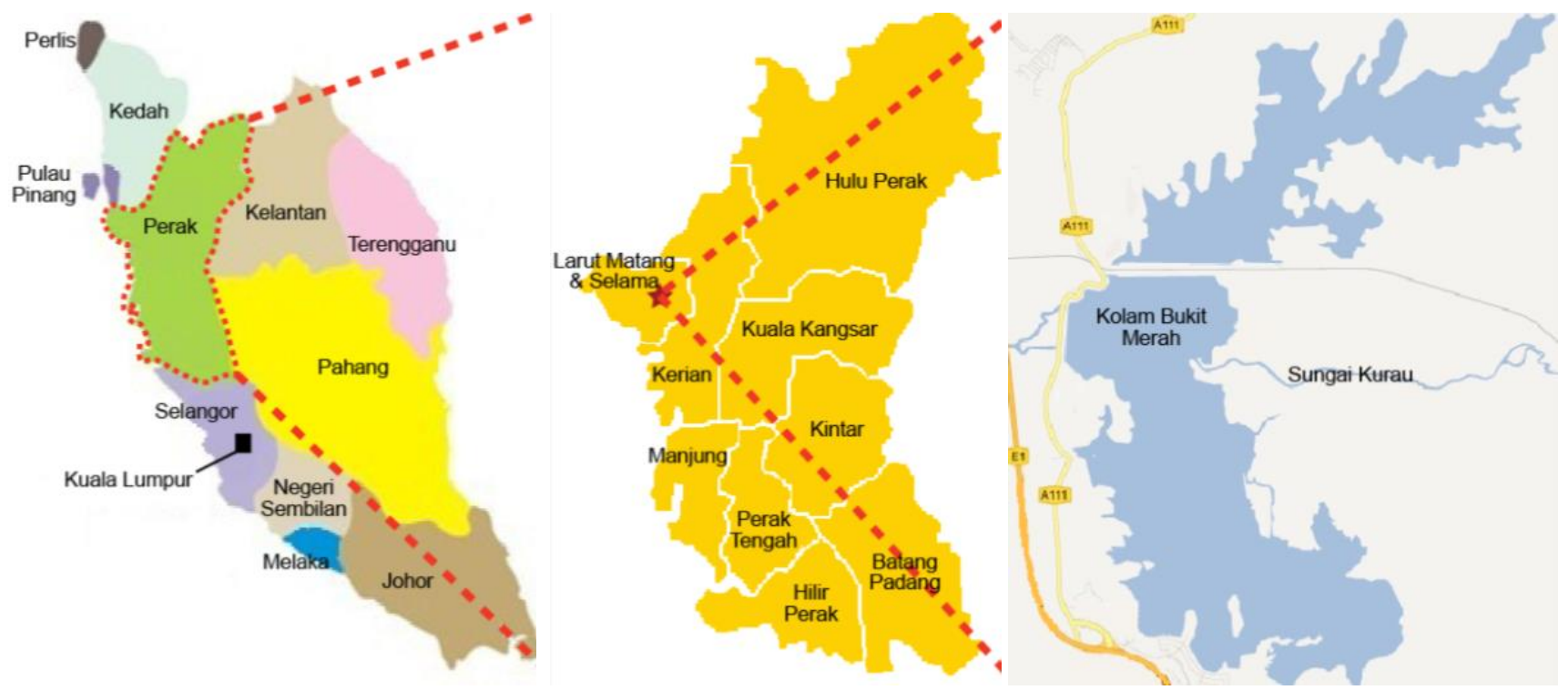

Figure 1. Bukit Merah Orang Utan Island (BMOUI), Perak, Malaysia

Table 1. Six categories of ecotourism visits (Chan and Baum 2007; Otto and Ritchie 1996) 


\begin{tabular}{ll}
\hline Category & Elements \\
\hline Hedonic & Excitement, enjoyment, and memorable experiences in terms of wildlife and natural habitat. \\
Interactive & $\begin{array}{l}\text { Involvement in seeing and spotting wildlife and fulfilling wants and needs } \\
\text { Positive communications between guests and the lodge staff, guides, and group members . } \\
\text { Chances to meet other people, especially staff and group members. }\end{array}$ \\
Now, unique, and different experiences (never been before, first time seeing wildlife in the wild, experience \\
of a lifetime).
\end{tabular}

The sampling survey provided the tourists with an overview of ecotourism and raised their awareness of the eco-park concept for sustainable tourism. This included five principles that were recognized earlier, as follows: the presence of a protective center, benefit to inhabitants, return to nature, responsibility, and theory of primitive wilderness. These were added to the six elements of the tourist perception by Chan and Baum (2007) and Otto and Ritchie (1996). The elements of the theory comprised hedonic, interactive, novelty, comfort, safety, and stimulation values (Table 1).

The surveys consisted of several parts, including ecotourism elements and recommendations from the respondents. The questionnaires included many aspects of ecotourism valuations based on previous studies by Chan and Baum (2007) and Otto and Ritchie (1996) to indicate the understanding of the ecotourism visit. The categories employed a 5-point Likert scale from 'strongly disagree' (1) to 'strongly agree' (5) (Chan and Baum 2007). In the questionnaires, the respondents were asked to respond to 10 different statements that represented the six expressive values of ecotourism experiences in BMOUI.

Cronbach's alpha and correlation test were used for analyzing the tourist experience data based on the six tourism elements using the Statistical Package for the Social Sciences (SPSS) v.20 software. Descriptive analysis was used for the qualitative data. The valuations of the six ecotourism elements were conducted by carrying out descriptive analysis of the responses using a scale based on Chan and Baum (2007) and Otto and Ritchie (1996), where a result below $40 \%$ was considered low, $41-70 \%$ was medium, and $71-100 \%$ was high. In addition, the WTP of tourists for the entrance fees to BMOUI was determined via the "bidding game," using a simple version of the contingent valuation method (CVM). The price was indicated as being either lower than or equal to their WTP, which was determined based on what proposed amount the individual would accept to pay, with a minimum of RM10, maximum of RM100 or possible exceed than RM100. The distributed questionnaires assembled general input about the visitors and their understanding of BMOUI as an ecotourism center.
There were also questions designed to determine the characteristics of paying and the mean value of WTP for the entrance fee at BMOUI. They allowed respondents to state whether they would be willing to pay if the current charge for the entrance fee was increased. The surveys were intended to determine the visitors' WTP for a higher fee level and honest opinion on the visit to BMOUI. The WTP approach was called a "bidding game" because there were different price ranges to be chosen to suit Malaysian and foreign visitors. The game gave visitors the choice to react to the question until their maximum WTP was established.

\section{RESULTS AND DISCUSSION}

\section{Tourists' valuation on six expressive elements of ecotourism experiences at BMOUI}

The first objective of this study was to determine all six expressive valuations describing the quality of the tourists' visits to BMOUI. The reliability test was performed for this post-visit questionnaire, and Cronbach's alpha showed that it was reliable, at 0.97. Based on the hedonic value, most of the respondents gave moderate positive feedback (44.8\%) on the survey given. The second element was an interactive experience in BMOUI, which had a moderate interactive value $(42.35 \%)$. The analysis indicated that BMOUI's visitors have a medium novelty experience, as the average positive response was $42.5 \%$. The results also indicated other tourism elements, with the following findings: medium comfort value $(42.5 \%)$, medium stimulation value $(42.7 \%)$, and low-security value $(37.15 \%)$.

\section{Tourist's WTP for the entrance fee}

The maximum WTP obtained from the bidding game was RM100 (Figure 3), while the minimum WTP was RM10. These values were significant in portraying how the respondents valued their trip and experience at BMOUI. In the analysis, the WTP per person per visit to BMOUI was RM54.90, which is quite high, in the price range of RM5160 , compared with the current entrance fee of RM30. 


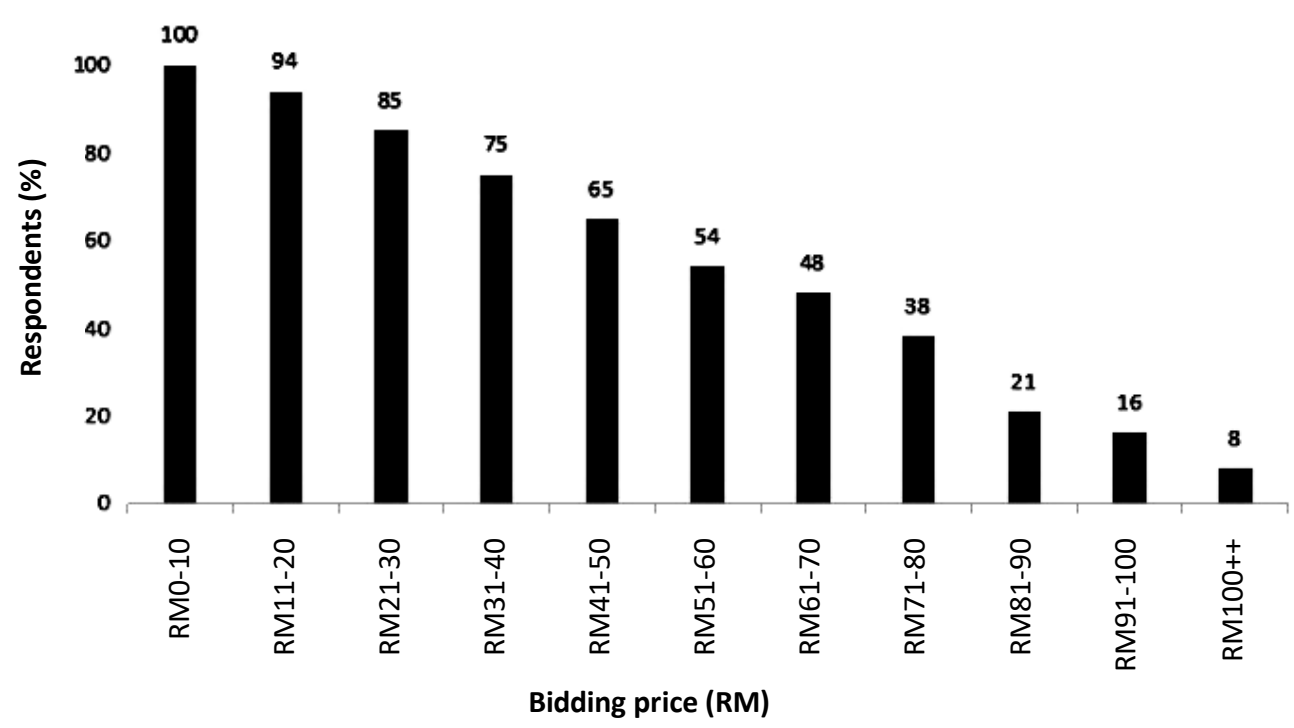

Figure 3. The maximum willingness to pay for the tourist to purchase the entrance fee to BMOUI, Perak, Malaysia

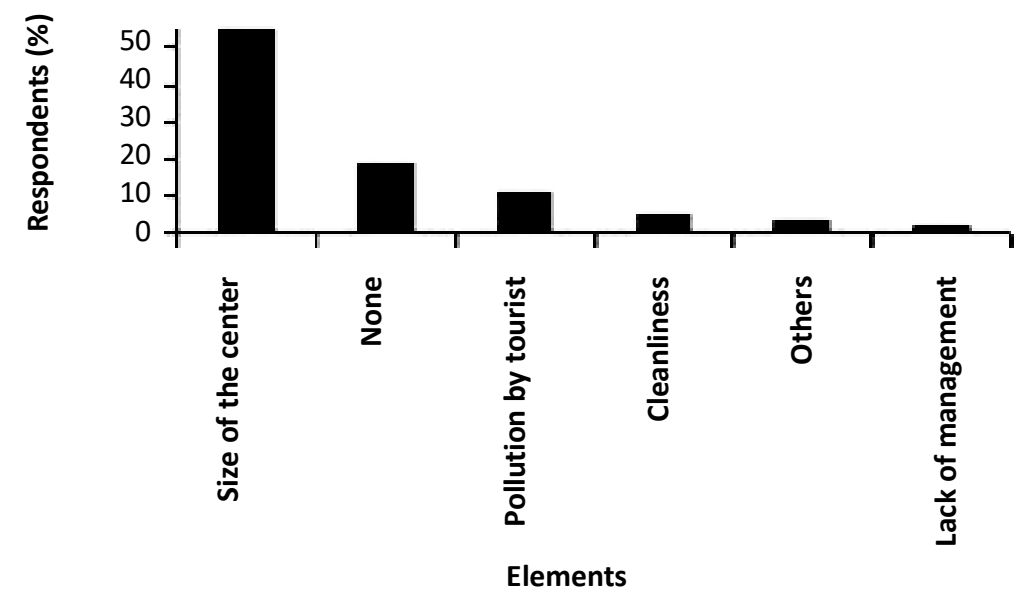

Figure 4. Improvement criteria required by BMOUI, Perak, Malaysia that suggested by tourists during the tour

\section{Tourists' suggestions and recommendations}

For this section, tourists were asked to respond to five elements, comprising both open-ended and closed-ended questions on their honest suggestions and recommendations related to the visit to BMOUI. The last part of this section was the result of the "bidding game" that was performed to determine the respondents' WTP for the entrance fee. The first question was constructed to determine the suitability of the tour to the minimum fee, the RM30 ticket that they bought. The analysis summarized that most of the respondents $(96.0 \%)$ agreed that the tour was suitable to be organized like it was at present in comparison with the price of the ticket they bought; only a small proportion of the respondents $(4.0 \%)$ disagreed with this. The reasons for the latter respondents' disagreement were that the ticket was too pricey and the duration of the tour was too short.

The respondents were given a series of options about unsupportive aspects of BMOUI that they noticed during the tour. This question aimed to motivate the center to upgrade in a positive way. It was found that the highest percentage of respondents, $57.0 \%$, claimed that the size of the center was a problem to them (Figure 4). The second most frequent response was "none" at $18.0 \%$, followed by "pollution by tourists" at 13.0\%, "cleanliness" at 6.0\%, "other" at 4.0\%, and "lack of management" at $2.0 \%$.

Some of the respondents were willing to share their opinions about how improvements can be made at BMOUI. Most of the respondents felt distracted by the thick fences along the trail, but we considered that the fences were in place to ensure the safety of the tourists. The management should inform the tourists about the purpose of the fences, as the orangutan could cause harm to people if they felt threatened. There have been several cases reported by the rangers in which an orangutan escaped their area before the establishment of the fences, posing a risk for tourists. Tourists should be noted, as they will be more careful and the orangutan will travel around the habitat comfortably. However, credit should be given to the management for the establishment of the safety signboards and information that could be seen around the center. 
The respondents were asked about the appropriateness of the ticket price for the tour provided. The question was the reverse of the first question in this section. In the first question, we wanted to determine the appropriateness of the tour, in the tourists' opinion, for the price they paid; in the second, we wanted to know if they thought the price matched the tour they received. The analysis found that most of the respondents $(89.0 \%)$ agreed that the ticket price was worth the experience that they had at BMOUI, whereas $11.0 \%$ did not agree with the ticket price. All the six documented values were thought to be the main contributors toward the customers' satisfaction on the tour. Overall, there was a significant positive correlation between all six expressive valuations with the appropriateness of the ticket price for the tour provided as hedonic. All six elements would influence the relevancy of the ticket price for entering BMOUI (Table 2).

\section{Discussion}

\section{Hedonic value}

The analysis of hedonic value illustrated that BMOUI's visitors could have a medium hedonic experience, as the average positive responses reached $44.8 \%$. Malone et al. (2014) identified the strong relationship between hedonism and ethical tourism. They claimed that high intensity of hedonism will help tourists in rationalizing and reinforcing current and intended behavior. In this case, it will surely contribute towards raising awareness about wildlife (orangutan) conservation issues. As an example, for the statement "I feel welcomed here" on the last question, most of the respondents strongly agreed $(62.0 \%)$. This gives us a picture of the tourists' overview of their overall visit, where feeling welcomed contributed toward the excitement and need to feel more emotional expression. This may cause tourists to repeat their visits and again contribute to raising awareness through participation in the future.

\section{Interactive experience}

This element contributes to the awareness of wildlife conservation in the ecotourism area. Knapp (2004) carried out research on iguana-based ecotourism activities in Moka Ecolodge in the Caribbean. This place was identified as one of the good ecotourism sites, as its management authorities attract tourists and members of the local communities (Knapp 2004). The management organized attractive activities to encourage the development of interactive skills and knowledge about wildlife conservation among the community and tourists (Knapp 2004). Thus, it will eventually function as a catalyst for spreading awareness concerning wildlife (Knapp 2004). This could be done at BMOUI as well, with a view to attracting more tourists to experience the site; thus, authorities' desire to maintain the site can be enhanced, and at the same time, the objectives of the site can be achieved. In another study, Duffy (2014) considered interactive elephant-based ecotourism in southern Africa. The research concluded that the interactive experience is significant in encouraging good tourism methods by management (Duffy 2014). The sustainable implementation in managing wildlife based on ecotourism areas will assist in spreading awareness on wildlife species conservation (Duffy 2014).

\section{Novelty experience}

The third element that was analyzed was the tourists' valuation responses toward novelty experiences at BMOUI. The analysis summarized that BMOUI's visitors have a medium novelty experience, as the average positive responses reached $42.5 \%$. According to Cohen (1972), the readiness of the tourist to face novelty experiences could be driven by the increased level of tourist awareness concerning the outer world (Cohen 1972). In this case, tourist awareness of orangutan conservation at BMOUI could be affected by the tourists' readiness to have new experiences and interactions with the orangutan. In addition, the tourists were willing to spend their time to have a new experience while developing knowledge about primates and conservation or anything related to orangutan (Cohen 1972).

\section{Comfort experience}

The tourists' valuation of the comfort experience at BMOUI was the fifth element that was analyzed. The analysis summarized that BMOUI's visitors could have a medium comfort experience, as the average positive responses reached $43.2 \%$. The environmental issues concerning social and economic development should be linked with ecotourism management authorities to achieve the objective for sufficient industry (Libosada 2009). A comfortable ecotourism area will produce a satisfied customer, resulting in a strong future for building sustainable ecotourism areas (Libosada 2009). Thus, the satisfaction of different parties-including the operators, stakeholders, local communities, and visitors as customers - could be successfully obtained (Libosada 2009). This win-win situation would contribute toward better management of the ecotourism site and help in spreading conservation awareness (Libosada 2009).

Table 2. Correlation between all six tourist's expressive ecotourism experience valuations with the relevancy of the ticket price with the tour

\begin{tabular}{lccccccc}
\hline \multicolumn{1}{c}{$\begin{array}{c}\text { Expressive } \\
\text { Values }\end{array}$} & Hedonic & Interactive & Novelty & Comfort & Stimulation & Safety & $\begin{array}{c}\text { Relevancy of the ticket } \\
\text { price with the tour } \\
\text { provided }\end{array}$ \\
\hline Hedonic & & $0.869^{* *}$ & $0.703^{* *}$ & $0.746^{* *}$ & $0.744^{* *}$ & $0.553^{* *}$ & $0.232^{* *}$ \\
Interactive & $0.869^{* *}$ & & $0.762^{* *}$ & $0.738^{* *}$ & $0.694^{* *}$ & $0.487^{* *}$ & $0.263^{*}$ \\
Novelty & $0.703^{* *}$ & $0.762^{* *}$ & & $0.703^{* *}$ & $0.694^{* *}$ & $0.519^{* *}$ & $0.217^{*}$ \\
Comfort & $0.746^{* *}$ & $0.738^{* *}$ & $0.703^{* *}$ & & $0.706^{* *}$ & $0.567^{* *}$ & $0.247^{*}$ \\
Stimulation & $0.744^{* *}$ & $0.694^{* *}$ & $0.649^{* *}$ & $0.706^{* *}$ & & $0.678^{* *}$ & $0.203^{*}$ \\
Safety & $0.553^{* *}$ & $0.487^{* *}$ & $0.519^{* *}$ & $0.567^{* *}$ & $0.678^{* *}$ & & $0.303^{*}$ \\
\hline
\end{tabular}

Note: $* *$ Correlation is significant at $\mathrm{p}<0.01,{ }^{*}$ Correlation is significant at $\mathrm{p}<0.05$ 
The comfort value was definitely portrayed and achieved through the visits, as $71.0 \%$ of the respondents strongly agreed that BMOUI provided a peaceful place and that the tourists feel comfortable during the tour. According to $\mathrm{Lu}$ and Stepchenkova (2012), there are six categories of tourist satisfaction that can contribute to a comfortable visit to an ecotourism site, which is the room setting (if the tourists are sleeping there), natural view, the operator's service, food, location, and value for money. In addition, the hygiene factor was recognized by Herzberg et al. (1959) as one of the elements contributing to customer satisfaction and staff motivation to work better in a comfortable environment.

\section{Stimulation}

The next element was tourists' responses toward the stimulation experience in BMOUI. Overall, the responses showed that BMOUI's visitors could have a medium stimulation experience, with the average mean score reaching $42.7 \%$, obtained from the mean score for the selection of 4 and 5 on the scale, illustrating a positive response. A study by Holden and Sparrowhack (2002) found that protecting the site from harm while trekking stimulated the trekkers of Annapurna in Nepal. For instance, they needed to prevent any littering along with trekking sites so that other trekkers could have fun and enjoy the natural environment as well (Holden and Sparrowhack 2002). The BMOUI also offers untouched natural views to serve as a natural environment, as the island provides a real habitat for wildlife, especially orangutans. In addition, tourists feel stimulated to conserve the orangutan and willing to contribute for conservation purposes.

\section{Safety}

The last element was tourists' valuation on the safety experience during the visit to BMOUI. The analysis summarized that BMOUI's visitors could have quite a low safety experience, as the average positive responses reached $37.15 \%$. Bentley et al. (2010) recorded some common incidents that could happen during ecotourism activities, which were slips, trips, and falls. Some of the common risks that have been recorded are mismanagement by the operators, weather, attitude of the tourists, and failure of the operator to follow safety management practices (Bentley et al. 2010). Collaboration between management operators and tourists could minimize these risks (Bentley et al. 2010).

\section{WTP}

According to Ahmad (2009), the average WTP valuation is the average of the bid responses throughout the price group. Valuation of WTP helps illustrate the need for ecotourism activities, although it is difficult to give them a monetary value (Maharana et al. 2000). The effort would delineate the conservation needs of the conservation area's subject, such as the orangutan at BMOUI. Thus, it will spread awareness among the tourist's friends and relatives. In Samdin (2008) study, the WTP in Taman Negara was investigated using the CVM for determining the maximum amount of the entrance fees for non-market goods. The study provided information to the operators to justify reasonable entrance fees for both licenses and permits (Samdin 2008). The researcher showed that both operators and customers would have a fair option and satisfaction could be fulfilled if the appropriate price point were selected (Samdin 2008).

In conclusion, six expressive valuations on ecotourism experiences, namely hedonic, interactive, novelty, comfort, stimulation, and safety values were successfully accessed. Respondents were satisfied with the trip provided with little negative feedback and RM54.90 per tourist per visit was the mean value was determined using the average of the bid responses. This study can identify BMOUI as a potential ecotourism site for development. Potential stakeholders, researchers, and policymakers could help managers to support the operator's effort to raise awareness on primate conservation, especially in Peninsular Malaysia. In the future, further research could be conducted with a wider range of respondents and a longer study duration to gather reliable data for supporting the initiative while contributing to spreading conservation practices and awareness throughout the world community.

\section{ACKNOWLEDGEMENTS}

The authors are deeply indebted to Yayasan Emkay and Bukit Merah Orang Utan Island Foundation (Tan Sri Datuk Mustapha Kamal bin Abu Bakar) for providing us funding, facilities, and assistance. We also thank the Department of Wildlife and National Parks, Malaysia (PERHILITAN). Research methods reported in this research adhered to the legal requirements of Malaysia and were approved by the Department of Wildlife and National Parks under research permit (JPHL\&TN (IP):100-6/1/14 Jld 2 (40). The authors acknowledge Universiti Kebangsaan Malaysia for providing funding (TD-2014-022). This research was also supported by Grant ST 2018-020 under Yayasan Emkay.

\section{REFERENCES}

Abdul-Latiff MAB, Baharuddin H, Abdul-Patah P, Md-Zain BM. 2019a. Is Malaysia's banded langur, Presbytis femoralis femoralis, actually Presbytis neglectus neglectus? Taxonomic revision with new insights on the radiation history of the Presbytis species group in Southeast Asia. Primates 60 (1): 63-79. DOI: 10.1007/s10329-018-0699-y

Abdul-Latiff MAB, Najmuddin MF, Haneef SK, Nabil A, Shahrool-Anuar R, Md-Zain BM. 2019b. Transforming ranging behaviour of Schlegel's Banded Langur (Presbytis neglectus) into PrimaTourism product. IOP Conf Ser Earth Environ Sci 269 (1): 012005. DOI: 10.1088/1755$1315 / 269 / 1 / 012005$.

Abdul-Latiff MAB, Najmuddin MF, Haneef SK, Nabil A, Shahrool-Anuar R, Md-Zain BM. 2019c. PrimaTourism: Preliminary study on activity budget of Presbytis neglectus with insights on local people perception on the product's potential economic value in Johor. IOP Conf Ser Earth Environ Sci 269 (1): 012006. DOI: 10.1088/1755-1315/269/1/012006

Ahmad SA. 2009. Visitor's Willingness To Pay For An Entrance Fee: Case Study of Marine Parks in Malaysia. [Dissertation]. University of Glasgow.

Ahmad SZ, Pandey DN. 2016. Development and assessment of ecotourism in Panna National Park (Madhya Pradesh), India. Intl J Appl Universal Res 3 (1): 1-5.

Aznie RCR, Asmah A, Zaini S, Rahim MN, Rosmiza MZ, Novel L, Fuad MMJ, Jumaat A, Choy EA, Hussain MY. 2012. Dilema perumahan 
penduduk tempatan bukit fraser dalam arus pembangunan ekopelancongan. Geografia Malays J Soc Space 8 (8): 47-54. [Malaysian]

Bently TA, Carter C, Page SJ. 2010. Adventure and ecotourism safety in Queensland: Operator experiences and practice. Tour Manag 31 (5): 563-571. DOI: 10.1016/j.tourman.2009.03.006

Chan JKL, Baum T. 2007. Ecotourist's perception of ecotourism experience in Lower Kinabatangan, Sabah, Malaysia. J Sustain Tour 15 (5): 574590. DOI: $10.2167 /$ jost679.0

Chougule B. 2011. Environmental carrying capacity and ecotourism development. Intl J Econ 4 (1): 45-54

Choy EA, Aznie RCR, Lyndon N, Abdullah MA, Adam JH. 2012. Ekopelancongan dan analisis sosioekonomi komuniti Ulu Dong. Geografia Malays J Soc Space 8 (9): 46-52. .

Chu-Chai W, Zhang-Wen W, Qun-Ming Z, Wei-Hua H. 2007. A study on the concept of ecotourism. Tourism Tribune 2007 (1): 67-71.

Cohen E. 1972. Toward a sociology of international tourism. Soc Res 39: 164-189.

Dharmalingam S. 2016. Respiratory tract infection in infant orangutan (Pongo pygmaeus) at Orang Utan Island, Bukit Merah, Perak, Malaysia. Pyrex J Med Med Sci 3 (2): 5-9.

Duffy R. 2014. Interactive elephants: nature, tourism and neoliberalism. Ann Tour Res 44: 88-101. DOI: 10.1016/j.annals.2013.09.003

Herzberg F, Mausner B, Synderma BB. 1959. Motivation To Work. John Wiley \& Sons, New York.

Holden A, Sparrowhawk J. 2002. Understanding the motivations of ecotourists: the case of trekkers in Annapurna, Nepal. Intl J Tour Res 4 (6): 435-446.

Kamaluddin SN, Yaakop S, Idris WMR, Dharmalingam S, Rovie-Ryan JJ, Md-Zain BM. 2018. Genetic identification of critically endangered orangutans in captivity. J Sustain Sci Manag 13: 57-68.

Kamaluddin SN, Dharmalingam S, Md-Zain BM. 2019. Positional behavior of captive Bornean Orangutan (Pongo pygmaeus) at Bukit Merah Orangutan Island, Perak, Malaysia. Biodiversitas 20 (2): 425-429. DOI: $10.13057 /$ biodiv/d200217.

Knapp CR. 2004. Ecotourism and Its Potential Impacts on Iguana Conservation in the Caribbean. In: Alberts AC, Carter RL, Hayes WK, Martins EP (eds.). Iguanas: Biology and Conservation. University of California Press, Berkley

Libosada CMJ. 2009. Business or leisure? economic development and resource protection: concepts and practices in sustainable ecotourism.
Ocean Coastal Manag 52: 390-394. DOI: 10.1016/j.ocecoaman.2009.04.004.

Lu W, Stepchenkova S. 2012. Ecotourism experiences reported online: classification of satisfaction attributes. Tour Manag 33: 702-712. DOI: 10.1016/j.tourman.2011.08.003

Maharana I, Rai SC, Sharma E. 2000. Valuing Ecotourism in a Sacred Lake of The Sikkim Himalaya, India. Environ Conserv 27 (3): 269-277.

Malone S, McCabe S, Smith AP. 2014. The role of hedonism in ethical tourism. Ann Tour Res 44: 241-254. DOI: 10.1016/j.annals.2013.10.005.

Md-Zain BM, Abdul-Manan MN, Abdul-Latiff MAB, Mohd-Daut N, Mohd-Ridwan AR. 2019. Positional behavior of Robinson's banded langur (Presbytis femoralis robinsoni). J Sustain Sci Manag 14 (5): 164-174.

Najmuddin MF, Haris H, Shahrool-Anuar R, Norazlimi N, Md-Zain BM, Abdul-Latiff MAB. 2019. PrimaTourism: Plant selection by Schlegel's Banded Langur Presbytis neglectus in Johor. IOP Conf Ser Earth Environ Sci 269 (1): 012036. DOI: 10.1088/1755-1315/269/1/012036.

Osman NA, Abdul-Latiff MAB, Mohd-Ridwan AR, Yaakop S, Nor SM, Md-Zain BM. 2020. Diet composition of the wild Stump-Tailed Macaque (Macaca arctoides) in Perlis State Park, Peninsular Malaysia, using a chloroplast tRNL DNA metabarcoding approach: a preliminary study. Animals 10 (12): 2215. DOI: 10.3390/ani10122215.

Otto JE, Ritchie JRB. 1996. The service experience in tourism. Tour Manag 17 (3): 165-174. DOI: 10.1016/0261-5177 (96)00003-9

Ouattara B, P'erez-Barahona A Strobl E. 2019. The dynamic implications of tourism and environmental quality. J Public Econ Theor 21: 241264. DOI: 10.1111/jpet.12330.

Ruslin F, Matsuda I, Md-Zain BM. 2019. The feeding ecology and dietary overlap in two sympatric primate species, the Long-tailed macaque (Macaca fascicularis) and Dusky langur (Trachypithecus obscurus obscurus) in Malaysia. Primates 60 (1): 41-50. DOI: 10.1007/s10329018-00705-w.

Samdin Z. 2008. Willingness to Pay in Taman Negara: A Contingent Valuation Method. Intl J Econ Manag 2 (1): 81-94. .

Siti-Kauthar M, Najmuddin MF, Md-Zain BM, Abdul-Latiff MAB. 2019. PrimaTourism: Preliminary study on activity budget of Dusky leaf monkey Trachypithecus obscurus obscurus in Bukit Soga Perdana, Batu Pahat, Johor. IOP Conf Ser Earth Environ Sci 269 (1): 012045. DOI: $10.1088 / 1755-1315 / 269 / 1 / 012045$. 